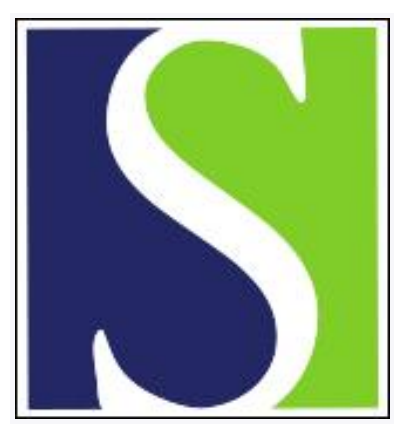

Scand J Work Environ Health 1998;24(6):473-480

https://doi.org/10.5271/sjweh.371

Issue date: Dec 1998

Paternal exposure to pesticides and congenital malformations

by García AM, Benavides FG, Fletcher T, Orts E

Key terms: agriculture; birth defect; epidemiologic study; expert assessment of exposure

This article in PubMed: www.ncbi.nlm.nih.gov/pubmed/9988089

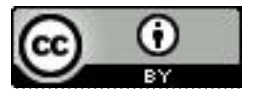




\title{
Paternal exposure to pesticides and congenital malformations
}

\author{
by Ana M García, PhD, ${ }^{1}$ Fernando G Benavides, PhD, ${ }^{2}$ Tony Fletcher, PhD, ${ }^{3}$ Enrique Orts, $M D^{4}$
}

\begin{abstract}
García AM, Benavides FG, Fletcher T, Orts E. Paternal exposure to pesticides and congenital malformations. Scand J Work Environ Health 1998;24(6):473-480.

Objectives A case-referent study with 261 matched pairs was carried out in 8 hospitals of Comunidad Valenciana, Spain, to assess the relation between occupational exposure to pesticides and selected congenital malformations. In this paper, the results concerning paternal exposure are presented.

Methods The parents of the case patients and the referents were interviewed to collect information about exposure to pesticides and potential confounding variables. Detailed information on direct involvement in the handling of pesticides was collected for the interviewees involved in agricultural activities during a previously defined period in relation to conception and pregnancy. Exposure data were reviewed by 2 experts who assigned ordinal scores for the probability and intensity of exposure to pesticide classes and active ingredients.

Results The dichotomous analysis of exposure (absent, present) yielded some increased risks, although not statistically significant, for aliphatic hydrocarbons [adjusted odds ratio (adjusted OR) 2.05, 95\% confidence interval (95\% CI) 0.62-6.80], inorganic compounds (adjusted OR 2.02, 95\% CI 0.53-7.72), and glufosinate (adjusted OR 2.45, 95\% Cl 0.78-7.70), and a significant association for pyridil derivatives (adjusted OR 2.77, 95\% CI 1.19-6.44). The analysis based on the experts' scores ( 2 levels of exposure) showed some consistent associations for these compounds.

Conclusions This research indicates a possible risk of congenital malformations for paternal exposure to some pesticides, notably, pyridils, aliphatic hydrocarbons, inorganic compounds, and glufosinate. It did not find an increased risk for paternal exposure to pesticides in the classes of organophosphates, carbamates, organochlorines, chloroalkylthio fungicides and organosulfurs. These findings warrant further investigation.
\end{abstract}

Key terms agriculture, birth defects, epidemiologic study, expert assessment of exposure.

The etiology of many congenital malformations remains substantially unknown, the number of proved human teratogens being relatively low. It has been estimated that between $60 \%$ and $70 \%$ of the cases of human malformation are of unknown origin (1). Most of the published etiologic studies focus on maternal exposures and conditions. However, the need to determine any significant risks of male-mediated developmental toxicity, including congenital malformations and other adverse outcomes, has been repeatedly asserted (2). Mechanisms proposed for paternally-mediated toxic chemical risks for birth defects include (i) direct effects on germ cells and (ii) secondary maternal exposure to the substance through the presence of the toxin in seminal fluids or through home contamination by workclothing or work materials or equipment $(3,4)$.

Experimental studies indicate that many pesticides have teratogenic potential $(5-7)$. Several epidemiologic studies have evaluated the teratogenic potential of pesticides, and some of them have focused on occupational paternal exposure, mainly among agricultural workers (8-28). Limited accuracy for exposure assessment is a frequent problem in many of these studies. Classifying the exposure into particular chemical categories or according to the active ingredients of pesticides is generally not considered (4).

Exposure assessment based on information collected in personal interviews or questionnaires can be improved

1 Department of Preventive Medicine and Public Health, University of Valencia, Valencia, Spain.

2 Department of Experimental and Health Sciences, University Pompeu Fabra, Barcelona, Spain.

3 Environmental Epidemiology Unit, Department of Public Health and Policy, London School of Hygiene and

Tropical Medicine, University of London, London, United Kingdom.

4 Trade Union Institute for Health, Environment and Work, Valencia, Spain.

Reprint requests to: Dr Ana M García, Departamento de Medicina Preventiva y Salud Pública, EU Relaciones Laborales Universidad de Valencia, Avda Tarongers s/n 46022 Valencia, Spain. [E-mail: anagar@uv.es] 
through subsequent evaluation by hygienists or experts on the exposure(s) of interest (29). This approach has been widely applied in the field of occupational epidemiology, and some researchers have used it for evaluating exposure to pesticides $(30-33)$.

A case-referent study on the relationship between occupational exposure to pesticides among agricultural workers and selected congenital defects was carried out in Comunidad Valenciana, Spain. This paper reports the results regarding paternal exposure to specific pesticides, determined from a personal interview and subsequent experts' assessments of the exposure.

\section{Material and methods}

The case and reference material was selected from births in 8 public hospitals located in largely agricultural zones in Comunidad Valenciana during 2 consecutive years (1993-1994). The base population consisted of couples who resided in the catchment areas of the hospitals and who gave birth in the selected hospitals. The cases were identified through the discharge records of the hospitals, being live births up to the age of 1 year of the child during the study period in any of the selected hospitals. Only malformations or groups of defects with a relatively high prevalence at birth and a relation to pesticides in previous epidemiologic research were considered for study, including nervous system defects [International Classification of Diseases, ninth revision (ICD-9) codes 740.0 742.9], cardiovascular defects (ICD-9 745.0_-747.9), oral clefts (ICD-9 749.0-749.2), epispadia or hypospadias (ICD-9 752.6), musculoskeletal defects (ICD-9 754.0-756.9), and unspecified defects (ICD-9 759.7759.9). The reference material comprised live births matched with the cases by hospital and date of birth at a ratio of 1:1. Parents of the case and reference children were located and interviewed by telephone, when a telephone number was available in the hospital records, and face-to-face otherwise. The general questionnaire used in these interviews collected information on potential confounding variables and on activities with potential exposure to pesticides.

Altogether 336 cases and 355 referents were initially selected for the study. From them, the parents of 292 cases and 284 referents were located. The father or mother or both of 31 cases ( $11 \%$ of located families) and 23 referents ( $8 \%$ of located families) refused to be interviewed $(\mathrm{P}=0.30)$. Altogether 261 cases and 261 matched referents were finally included in the study. The distribution of the cases by selected groups of congenital malformations was nervous system ( $\mathrm{N}=37$ ), cardiovascular defect $(\mathrm{N}=117)$, oral clefts $(\mathrm{N}=18)$, hypospadias or epispadia $(\mathrm{N}=18)$, musculoskeletal defect $(\mathrm{N}=79)$, nonspecified anomalies $(\mathrm{N}=14)$. Some cases were classified into more than one group of defects.

\section{Exposure questionnaire}

A set of questions at the end of the general questionnaire assessed previous involvement in activities potentially related to pesticide exposure, including agricultural work and pesticide application. An acute risk period for exposure was defined as the 3 months preceding conception or during the 1 st trimester of pregnancy or both for the father and during 1 month before conception or during the 1st trimester of pregnancy or both for the mother. This choice was made according to postulated mechanisms for male- and female-mediated teratogenesis (4). The interviewees involved in agricultural activities during the acute risk period were subsequently interviewed face to face with a specific exposure questionnaire, which collected detailed information about the characteristics of agricultural work and exposure to pesticides, including the following topics: (i) crop characteristics (type, open air or greenhouse; size and location; time periods of work); (ii) pesticide treatments [time periods of application; activity during treatments; number of days of treatment; hours per day of treatment; equipment; pesticides applied, both free recall and prompted using a prompt list of 44 pesticides, selected because they were frequently used in Comunidad Valenciana (34) or because there was some toxicologic evidence of these pesticides acting as teratogens (5-7)]; (iii) other sources of occupational pesticide exposure (cleaning of equipment, mixing of chemicals); (iv) home contamination (washing of workclothes, pesticide storage, equipment storage); and (v) other relevant data (personal hygiene, personal protection, knowledge of health risk of pesticides, subjective assessment of risk, and perceived health effects because of pesticide exposure).

The main topics in the exposure questionnaire were validated against information gathered through the employers' interviews, direct observation, and a previously self-completed questionnaire (35). In general, the accuracy and reliability for the different items in the questionnaire were good, except for type of pesticides used and length of time of the treatments. The information for both variables was improved by introducing the following new topics to the exposure questionnaire: a prompt list for type of pesticides and the size of the treated area as a proxy measurement for the duration of treatment.

\section{Experts' exposure assessment}

The information collected in the exposure questionnaire was further assessed by 2 local experts, a public health physician involved in the Training Program for Pesticide Applicators in Comunidad Valenciana and an environmental engineer working at the Agriculture Department of the Local Administration. Each expert independently 
assessed each questionnaire, blinded to whether it pertained to the parent of a case or a referent. For each pesticide reported to have been handled by the interviewee the experts assessed probability, intensity of exposure, and self-confidence. The probability of exposure was defined as "the likelihood of having really been exposed to the quoted chemical". It was coded into 4 levels ( $1=$ none or very low, $2=$ possible or low probability, $3=$ probable, $4=$ very probable or sure). Intensity was defined as "the amount of the chemical that could have been absorbed by the interviewee through the skin and/or through breathing air (ie, concentration, without consideration of the duration of exposure)". It was coded into 4 levels as well ( $1=$ low or background, $2=$ moderate, $3=$ high, $4=v e r y$ high). Confidence was defined as "a judgement of the security of the expert on his scores according to the quality of the information available from the questionnaire and/or to his personal experience" (1=low, $2=$ moderate, $3=$ high, $4=$ =very high).

When the experts finished their independent assess" ments, there was a meeting with both of them, the research manager, and the supervisor of the interviewers. Hence every questionnaire was jointly reviewed and a consensus rating was obtained when there were discrepancies on the evaluations for probability and intensity. Only the consensus scores for probability and intensity were used for the analysis. Scores for confidence were equal or greater than 2 in every case.

\section{Analysis}

Risk estimates were calculated for all the selected congenital malformations jointly. Exposure to pesticides was analyzed considering the following main approaches: (i) exposure to the main chemical classes of pesticides and (ii) exposure to specific active ingredients. As the interviewees usually quoted trade names, this information was translated into active ingredients and classes.

Persons exposed versus those not exposed to the top 10 most frequently quoted chemical classes and active ingredients during the acute risk period were compared. Dose-response relationships were analyzed based on the experts' consensus scores and the duration of exposure. Exposed interviewees were categorized into 2 groups according to a composite index obtained from the multiplication of the experts' scores for probability and intensity, namely, those with composite indices of at least 9 and those below 9. This cut-off point corresponds to codes for probability and intensity of at least equal to 3 (respectively, "probable" or "very probable" and "high" or "very high"). For some classes and active ingredients an alternative cut-off at 7 was applied because very low numbers were found in the lower category. The duration of exposure was considered together with the experts' scores for intensity in the 2 duration indices obtained from the multiplication of the intensity score and the number of months exposed during the acute risk period or the mean number of hours per year handling pesticides during the acute risk period. These exposure indices were dichotomized based on the median. Cut-off points were decided before any calculation of the estimates for association.

Crude and adjusted odds ratios were estimated from univariate and multivariate conditional logistic regression models including selected potential maternal and paternal confounding variables. The data analysis was carried out using Stata statistical software (36).

\section{Results}

Figure 1 shows the distribution of the parents of the cases and referents in the study. In a prior analysis, a slightly increased risk was found for the direct handling of pesticides by the fathers and all selected malformations (adjusted OR 1.49, $\mathrm{P}=0.087$ ). As there were very few women directly handling pesticides and the active ingredients quoted for them were too scarce, the subsequent analysis by classes and by active ingredients was restricted to the fathers.

The total number of different trade names of pesticides quoted by the interviewees was 93 , corresponding to 78 active ingredients and 28 chemical classes of pesticides. Table 1 presents the distribution of the fathers of the cases and referents and the crude and adjusted estimates for the risk of exposure during the acute risk period to the most frequently quoted classes and active ingredients. The most frequently used classes among the fathers were organophosphates (reported by $72 \%$ of the interviewees handling pesticides during the acute risk period), pyridil derivatives (reported by $49 \%$ ), and carbamates (reported by $28 \%$ ). Regarding active ingredients, the most frequently quoted were the pyridil derivative herbicides diquat (48\%) and paraquat $(48 \%)$, followed by the herbicide glufosinate $(28 \%)$, the insecticides derived from petroleum oils $(27 \%)$, and the organophosphate insecticide dimethoate $(23 \%)$.

When the risk estimates for the categories of pesticides with the largest numbers, and thus the power for detecting an association, were considered, there was evidence of an increased risk for pyridil derivatives [adjusted OR $2.77,95 \%$ confidence interval $(95 \% \mathrm{CI}$ ) $1.19-6.44]$ but not for organophosphates. The categories of aliphatic hydrocarbons and inorganic compounds showed adjusted odds ratios above 2.0 as well, although the confidence intervals included unity. For the active ingredients, there was an increased risk for glufosinate, not statistically significant in the adjusted model (adjusted OR $2.45,95 \%$ CI $0.78-7.70$ ), but not for dimethoate (the main representative of the organophosphates). 


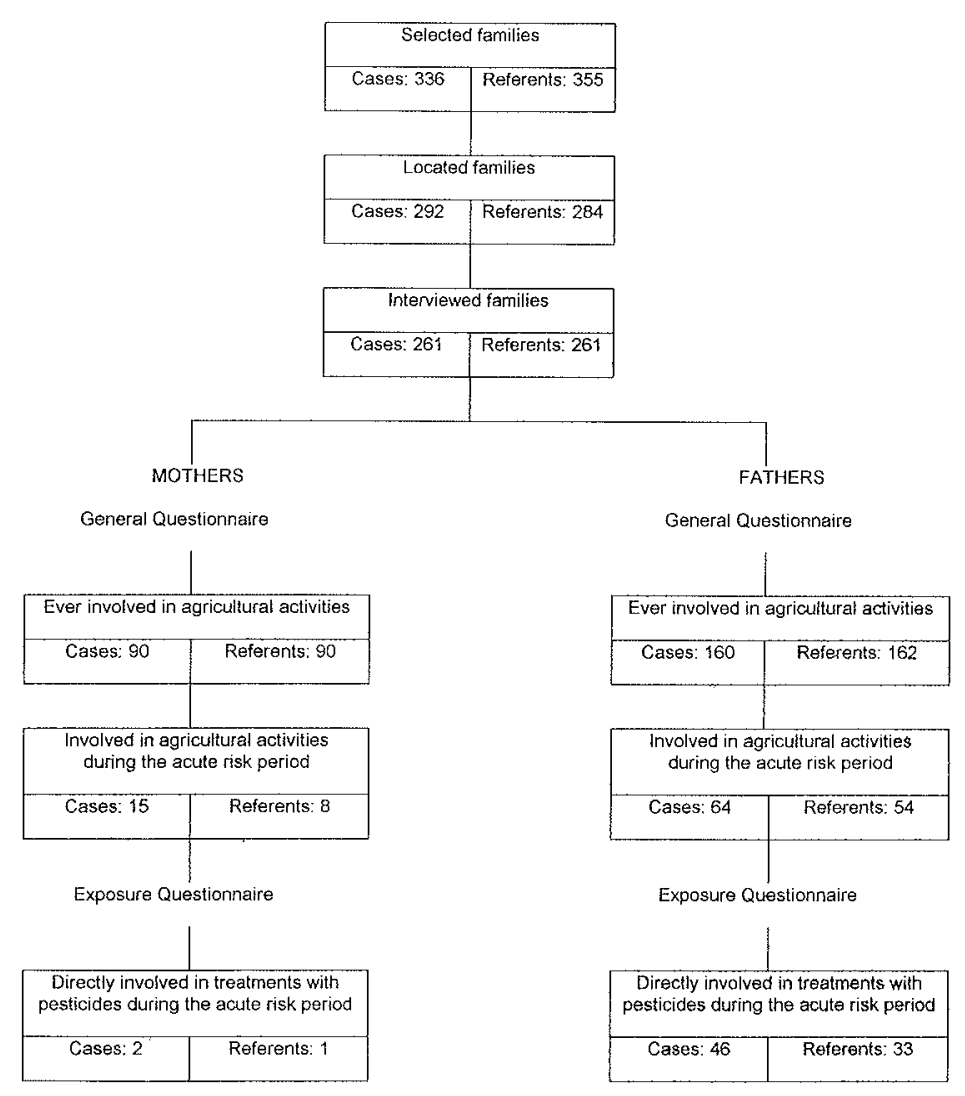

Figure 1. Distribution of the parents of the cases and referents in the study.

Table 1. Distribution of the fathers according to their exposure to reported chemical classes and active ingredients during the acute risk period. $\angle O R=$ odds ratio, $95 \% \mathrm{Cl}=95 \%$ confidence interval, MCPA $=4$-chloro-2-methylphenoxiacetic acid)

\begin{tabular}{|c|c|c|c|c|c|c|}
\hline & Cases $^{a}$ & Referentsa & Crude $0 \mathrm{R}^{\mathrm{b}}$ & $\begin{array}{c}95 \% \mathrm{Cl} \\
\text { of the crude OR }\end{array}$ & Adjusted $O R^{b, c}$ & $\begin{array}{l}95 \% \mathrm{Cl} \\
\text { of the adjusted } \mathrm{OR}\end{array}$ \\
\hline \multicolumn{7}{|l|}{ Chemical class ${ }^{d}$} \\
\hline Aliphatic hydrocarbons & 15 & 6 & 2.80 & $1.01-7.77$ & 2.05 & $0.62-6.80$ \\
\hline Carbamates & 10 & 12 & 0.82 & $0.34-1.97$ & 0.81 & $0.30-2.22$ \\
\hline Chloroalkylthio fungicides & 9 & 9 & 1.00 & $0.38-2.66$ & 1.00 & $0.31-3.29$ \\
\hline Chlorophenoxy herbicides & 13 & 8 & 1.63 & $0.67-3.92$ & 1.24 & $0.39-3.92$ \\
\hline Dithiocarbamates & 10 & 9 & 1.11 & $0.45-2.73$ & 1.32 & $0.42-4.18$ \\
\hline Inorganic compounds & 8 & 6 & 1.40 & $0.44-4.41$ & $\begin{array}{l}1.02 \\
2.02\end{array}$ & $\begin{array}{l}. .42-4.10 \\
0.53-7.72\end{array}$ \\
\hline Organochlorines & 10 & 9 & 1.11 & $0.45-2.73$ & 0.92 & $0.31-2.71$ \\
\hline Organophosphates & 31 & 26 & 1.14 & $0.64-2.05$ & 0.77 & $0.38-1.58$ \\
\hline Organosulfurs & 6 & 5 & 1.20 & $0.37-3.93$ & 0.82 & $0.18-3.65$ \\
\hline Pyridil derivatives & 27 & 12 & 2.18 & $1.07-4.45$ & 2.77 & $1.19-6.44$ \\
\hline \multicolumn{7}{|l|}{ Active ingrediente } \\
\hline Azinphos methyl (organophosphate) & 6 & 8 & 0.71 & $0.23-2.25$ & 0.46 & $0.11-2.03$ \\
\hline Captan (chloroalkylthio fungicide) & 7 & 8 & 0.86 & $0.29-2.55$ & 0.83 & $0.23-2.97$ \\
\hline Dicofol (organochlorine) & 7 & 8 & 0.88 & $0.32-2.41$ & 0.61 & $0.17-2.18$ \\
\hline Dimethoate (organophosphate) & 11 & 7 & $\begin{array}{l}0.00 \\
1.67\end{array}$ & $0.61-4.59$ & 0.95 & $0.29-3.16$ \\
\hline Fosetil-Al (organophosphate) & 8 & 6 & 1.17 & $0.39-3.47$ & 0.57 & $0.14-2.33$ \\
\hline Glufosinate (no general category) & 16 & 6 & 2.67 & $1.04-6.81$ & 2.45 & $0.78-7.70$ \\
\hline Glyphosate (organophosphate) & 20 & 15 & 1.23 & $0.59-2.56$ & 0.94 & $0.37-2.34$ \\
\hline Malathion (organophosphate) & 6 & 8 & 0.75 & $0.26-2.16$ & $\begin{array}{l}0.34 \\
0.30\end{array}$ & $0.06-1.43$ \\
\hline Methidathion (organophosphate) & 6 & 12 & 0.45 & $0.16-1.31$ & 0.27 & $0.06-1.17$ \\
\hline MCPA (chlorophenoxy herbicide) & 12 & 8 & 1.50 & $0.61-3.67$ & 1.20 & $0.37-3.84$ \\
\hline
\end{tabular}

a Number of interviewees reporting having handled the pesticide during the acute risk period.

${ }^{b} \mathrm{OR}$ and $95 \% \mathrm{Cl}$ obtained from univariate and multivariate conditional logistic regression models.

- Multivariate models were built for every class and active ingredient of pesticides by comparing persons stating having been exposed to the active ingredient during the acute risk period with those stating never having been exposed to that particular class or active ingredient and by adjusting by paternal (industrial worker, age $>40$ years) and maternal (spontaneous abortion, twins, drug consumption, heavy smoking, education and occupational situation) confounders.

"Ten most frequently quoted chemical classes in the exposure questionnaire.

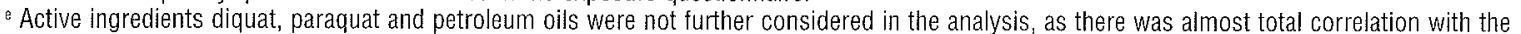
chemical classes pyridil derivatives (diquat and paraquat) and aliphatic hydrocarbons (petroleum oils). The remaining chemicals are the following 10 most frequently quoted active ingredients in the exposure questionnaire. 
An additional analysis including the experts' scores was carried out for the chemical classes and active ingredients showing the increased odds ratios in table 1 .

Table 2. Adjusted odds ratios (OR) for the risk of fathers' exposure to classes of pesticides based on experts' scores. $(95 \% \mathrm{Cl}=$ $95 \%$ confidence interval)

\begin{tabular}{|c|c|c|c|c|c|}
\hline \multicolumn{2}{|l|}{ Chemical class $s^{a, b, c}$} & $N$ & \multicolumn{2}{|c|}{$\begin{array}{c}\text { Adjusted } \\
0 \mathrm{R}^{\mathrm{d}}\end{array}$} & $\begin{array}{l}\text { Wald } \\
\text { teste }\end{array}$ \\
\hline \multicolumn{6}{|l|}{ Aliphatic hydrocarbons } \\
\hline No exposure & & 499 & 1.00 & & \\
\hline Composite index $<9$ & & 4 & 1.34 & $0.16-11.20$ & 0.789 \\
\hline Composite index $\geq 9$ & & 17 & 2.34 & $0.62-8.87$ & 0.212 \\
\hline \multicolumn{6}{|l|}{ Chlorophenoxy herbicides } \\
\hline No exposure & & 500 & 1.00 & & \\
\hline Composite index $<7$ & & 8 & 0.61 & $0.12-3.11$ & 0.556 \\
\hline Composite index $\geq 7$ & & 13 & 2.82 & $0.45-17.52$ & 0.267 \\
\hline \multicolumn{6}{|l|}{ Dithiocarbamates } \\
\hline No exposure & & 441 & 1.00 & & \\
\hline Composite index $<9$ & & 6 & 0.66 & $0.10-4.31$ & 0.661 \\
\hline Composite inde $x \geq 9$ & & 13 & 2.13 & $0.47-9.75$ & 0.330 \\
\hline \multicolumn{6}{|l|}{ Inorganic compounds } \\
\hline No exposure & & 506 & 1.00 & & \\
\hline Composite index $<9$ & & 2 & 0.62 & $0.02-17.19$ & 0.776 \\
\hline Composite index $\geq 9$ & & 12 & 2.55 & $0.57-11.38$ & 0.221 \\
\hline \multicolumn{6}{|l|}{ Pyridil derivatives } \\
\hline No exposure & & 466 & 1.00 & & \\
\hline Composite index $<7$ & & 15 & 3.97 & $1.13-13.99$ & 0.032 \\
\hline Composite index $\geq 7$ & & 24 & 2.15 & $0.76-6.08$ & 0.151 \\
\hline \multicolumn{6}{|l|}{ Aliphatic hydrocarbons } \\
\hline No exposure & & 499 & 1.00 & & \\
\hline Duration index (months) & $<$ median & 10 & 0.96 & $0.21-4.35$ & 0.953 \\
\hline Duration index (months) & $\geq$ median & 11 & 4.87 & $0.82-28.85$ & 0.081 \\
\hline Duration index (hours) & $<$ median & 9 & 1.24 & $0.25-6.11$ & 0.792 \\
\hline Duration index (hours) & $\geq$ median & 11 & 2,47 & $0.36-16.79$ & 0.356 \\
\hline \multicolumn{6}{|l|}{ Chlorophenoxy herbicides } \\
\hline No exposure & & 500 & 1.00 & & \\
\hline Duration index (months) & $<$ median & 7 & 0.42 & $0.08-2.37$ & 0.328 \\
\hline Duration index (months) & $\geq$ median & 14 & 3.12 & $0.57-16.92$ & 0.188 \\
\hline Duration index (hours) & $<$ median & 10 & 2.71 & $0.48-15.35$ & 0.261 \\
\hline Duration index (hours) & zmedian & 11 & 0.55 & $0.10-2.94$ & 0.484 \\
\hline \multicolumn{6}{|l|}{ Dithiocarbamates } \\
\hline No exposure & & 502 & 1.00 & & \\
\hline Duration index (months) & $<$ median & 9 & 0.50 & $0.09-2.73$ & 0.425 \\
\hline Duration index (months) & $\geq$ median & 10 & 3.30 & $0.64-17.02$ & 0.154 \\
\hline Duration index (hours) & $<$ median & 8 & 2.38 & $0.46-12.36$ & 0.301 \\
\hline Duration index (hours) & $\geq$ median & 11 & 0.72 & $0.13-3.88$ & 0.699 \\
\hline \multicolumn{6}{|l|}{ Inorganic compounds } \\
\hline No exposure & & 506 & 1.00 & & \\
\hline Duration index (months) & <median & 6 & 0.73 & $0.13-4.19$ & 0.725 \\
\hline Duration index (months) & $\geq$ median & 8 & 8.71 & $0.78-97.58$ & 0.079 \\
\hline Duration index (hours) & $<$ median & 7 & 4.84 & $0.55-42.79$ & 0.156 \\
\hline Duration index (hours) & $\geq$ median & 7 & 0.66 & $0.06-6.99$ & 0.731 \\
\hline \multicolumn{6}{|l|}{ Pyridil derivatives } \\
\hline No exposure & & 466 & 1.00 & & \\
\hline Duration index (months) & $<$ median & 17 & 2.51 & $0.78-8.04$ & 0.121 \\
\hline Duration index (months) & $\geq$ median & 22 & 3.03 & $0.99-9.26$ & 0.052 \\
\hline Duration index (hours) & $<$ median & 16 & 2.49 & $0.67-9.29$ & 0.174 \\
\hline Duration index (hours) & zmedian & 22 & 2.62 & $0.88-7.79$ & 0.083 \\
\hline
\end{tabular}

a Composite index $=$ probability $\times$ intensity (as scored by the experts).

${ }^{b}$ Duration index (months) $=$ intensity (as scored by the experts) $\times$ months working in agriculture during the acute risk period.

c Duration index (hours) = intensity (as scored by the experts) $\times$ hours per year being involved in pesticide treatments.

- Odds ratios and $95 \% \mathrm{Cl}$ obtained from multivariate conditional logistic regression models adjusted by maternal and paternal confounders (same as in table 1).

e Two-tailed P-values from the Wald test in the models.
The results of this analysis are presented in table 2 for the classes and in table 3 for the active ingredients. Some suggestive dose-response relationships are shown in these tables, but the confidence intervals were wide and mostly not significant. The classes and active ingredients showing the most consistent associations across the different indices were aliphatic hydrocarbons (eg, adjusted OR 4.87, $\mathrm{P}=0.081$, for the highest level of the duration index in months), inorganic compounds (eg, adjusted $O R$ $8.71, \mathrm{P}=0.079$, for the highest level of the duration index in months), pyridil derivatives (eg, adjusted OR 3.03, $\mathrm{P}=0.052$, for the highest level of the duration index in months) and glufosinate (eg, adjusted OR 9.98, $\mathrm{P}=0.049$, for the highest level of the duration index in hours).

\section{Discussion}

This study had a limited statistical power in the analyses for exposure or outcome or both subgroups. The consequences of lumping congenital malformations into groups not biologically or etiologically related have been repeatedly discussed (37). Although most teratogens are expected to cause several different defects (38) depending on

Table 3. Adjusted odds ratios (OR) for the risk of fathers' exposure to active ingredients of pesticides based on experts' scores. $(95 \% \mathrm{Cl}=95 \%$ confidence interval, MCPA $=4$-chloro- $2-$ methylphenoxiacetic acid)

\begin{tabular}{|c|c|c|c|c|}
\hline Active ingredient $\mathrm{a}^{\mathrm{a}, \mathrm{b}, \mathrm{c}}$ & $N$ & $\begin{array}{c}\text { Adjusted } \\
\mathrm{OR}^{d}\end{array}$ & d $95 \% \mathrm{Cl}$ & $\begin{array}{l}\text { Wald } \\
\text { test }^{8}\end{array}$ \\
\hline \multicolumn{5}{|l|}{ Glufosinate } \\
\hline $\begin{array}{l}\text { No exposure } \\
\text { Composite index }<7 \\
\text { Composite index } \geq 7\end{array}$ & $\begin{array}{c}499 \\
10 \\
12\end{array}$ & $\begin{array}{l}1.00 \\
3.20 \\
1.89\end{array}$ & $\begin{array}{c}0.60-17.02 \\
0.39-9.22\end{array}$ & $\begin{array}{l}0.173 \\
0.433\end{array}$ \\
\hline \multicolumn{5}{|l|}{$\mathrm{MCPA}^{\mathrm{e}}$} \\
\hline $\begin{array}{l}\text { No exposure } \\
\text { Composite index }<7 \\
\text { Composite index } \geq 7\end{array}$ & $\begin{array}{c}501 \\
9 \\
11\end{array}$ & $\begin{array}{l}1.00 \\
0.69 \\
2.59\end{array}$ & $\begin{array}{c}0.15-3.23 \\
0.39-17.11\end{array}$ & $\begin{array}{l}0.637 \\
0.324\end{array}$ \\
\hline \multicolumn{5}{|l|}{ Glufosinate } \\
\hline $\begin{array}{l}\text { No exposure } \\
\text { Duration index (months) <median } \\
\text { Duration index (months) } \geq \text { median } \\
\text { Duration index (hours) <median } \\
\text { Duration index (hours) } \geq \text { median }\end{array}$ & $\begin{array}{l}499 \\
11 \\
11 \\
11 \\
11\end{array}$ & $\begin{array}{l}1.00 \\
1.93 \\
3.48 \\
1.06 \\
9.98\end{array}$ & $\begin{array}{c}0.45-8.21 \\
0.56-21.75 \\
0.26-4.33 \\
1.01-98.31\end{array}$ & $\begin{array}{l}0.376 \\
0.182 \\
0.936 \\
0.049\end{array}$ \\
\hline \multicolumn{5}{|l|}{ MCPA } \\
\hline $\begin{array}{l}\text { No exposure } \\
\text { Duration index (months) <median } \\
\text { Duration index (months) } \geq \text { median } \\
\text { Duration index (hours) <median } \\
\text { Duration index (hours) } \geq \text { median }\end{array}$ & $\begin{array}{c}501 \\
8 \\
12 \\
10 \\
10\end{array}$ & $\begin{array}{l}1.00 \\
0.49 \\
2.96 \\
2.65 \\
0.50\end{array}$ & $\begin{array}{c}0.10-2.51 \\
0.52-16.75 \\
0.47-15.03 \\
0.09-2.85\end{array}$ & $\begin{array}{l}0.391 \\
0.221 \\
0.271 \\
0.433\end{array}$ \\
\hline
\end{tabular}

a Composite index $=$ probability $x$ intensity (as scored by the experts).

"Duration index (months) $=$ intensity (as scored by the experts) $\times$

months working in agriculture during the acute risk period

- Duration index (hours) $=$ intensity (as scored by the experts) $\times$ hours

per year being involved in pesticide treatments.

- Odds ratios and $95 \% \mathrm{Cl}$ obtained from multivariate conditional logistic regression models adjusted by maternal and paternal confounders (same as in table 1)

- Two-tailed P-values from the Wald test in the models 
different factors (eg, time of exposure), a proper assessment of the risk for specific defects or groups of defects was not possible in this study.

When compared with other methods of collecting data on occupational exposure for population-based case-referent studies (39), the combination of interviews and experts' assessment appeared to be the most attractive in terms of balance between costs (economical) and benefits (statistical power). The more standardized the experts' assessment process, the less place for random and nonrandom variability and exposure misclassification (40). However, alternative methods based on more systematic approaches have been proposed (41).

A potential misclassification of exposure derived from the experts' assessment process in this study would be completely nondifferential for cases and referents. Overreporting was expected to be at least partially corrected through the assignment of low probability scores. However, underreporting and its effects on the estimates will remain in our results. On the other hand, re-entry treated fields could be a source of pesticide exposure (7). Indeed, exposure derived from the environmental contamination or residues in drinking water or food will produce a background level of pesticide exposure in a majority of the population. These additional sources of pesticide exposure were not considered in this study.

Nondifferential misclassification due to underreporting could be the major problem regarding the recall of occupational exposures (42-44), and this could be the case for agricultural workers as well. However, regular behavior instead of sporadic exposure is likely to be re membered more accurately. This regularity is expected in agricultural activities highly related to seasonal patterns of activity. Furthermore, agricultural workers can be considered a special case regarding the recall of the occupational chemicals they are exposed to, as, in many cases, they decide what chemicals to use, they purchase them, they mix and apply them, and they register the costs for tax purposes. All these facts are expected to strengthen memory (45). In this research, the recall of specific pesticides was improved through the use of a prompt list. The acute risk period was relatively recent, extending only to a maximum of 4 years before the interview.

When there is simultaneous exposure to several chemicals, it can be difficult, or impossible, to measure their independent contributions to the risk. It has been pointed out that, for another pesticide to account for an observed association, the confounding pesticide must be as common an exposure as the pesticide of interest, but with even higher risk (45). On the other hand, interaction effects between pesticides is a likely possibility and toxicologic knowledge on this subject is very scarce (46). In addition, pesticide formulations not only include active ingredients, but also other chemicals are intention- ally or unintentionally present in the pesticide formulations (47). In this study we did not specifically evaluate a potential confounding or interaction effect between pesticides or other chemicals in the formulations.

Most of the epidemiologic studies on the risk of congenital malformations for paternal occupational exposure to pesticides $(4,8-28)$ do not find any association or only slightly increased risks. In a prevalence survey, Restrepo et al $(21,22)$ evaluated the risk of birth defects in a population of men and women working in floriculture fields in Colombia. A significant association was observed for paternal exposure in the survey (OR 1.53, 95\% Cl 1.04-2.25), but, in a subsequent case-referent study, with improved assessment of birth defects, the risk was not significant and showed an inverse relationship with length of employment. Rupa et al (23) observed a very increased risk for congenital malformations among male pesticide applicators in cotton fields in India (128 cases of congenital malformations in 4240 pregnancies among applicators, as compared with 2 cases in 3016 pregnancies in an unexposed group). However, scarce information was provided about the selection of the unexposed group and the measurement of the outcome. In a recent study carried out in Minnesota with pesticide applicators (27), slightly increased significant risks were observed for exposed fathers for all the birth defects (age-adjusted OR $1.41,95 \% \mathrm{CI} 1.18-1.69$ ) and for some major groups of defects.

In this study, organophosphates were the chemical class more widely reported by the interviewees, mainly being used as insecticides. No significant association was observed for exposure to organophosphates (adjusted OR 0.77 ), or for any of the more frequently used active ingredients of organophosphates. There was no evidence in our data of an increased risk for fathers exposed to captan or dicofol, the main representatives of chloroalkylthio fungicides and organochlorines, respectively. Only a few previous studies have had results related to occupational exposure to specific pesticides $(9,13,17$, 21,22 ), including a sulfanilamide, the 2,4,5-trichlorophenoxyacetic acid $(2,4,5-\mathrm{T})$, and captan.

Experimental research has yielded some positive findings regarding the reproductive and mutagenic effects of petroleum oils (aliphatic hydrocarbons), inorganic compounds (mainly represented by copper derivatives), and diquat and paraquat (pyridil derivatives) (7, 48-51). However, a recent review of the health effects of glufosinate concluded that it has no teratogenic, mutagenic, or carcinogenic potential (52).

We observed increased odds ratios for some classes and active ingredients. Those for pyridil derivatives were statistically significant, while those for aliphatic hydrocarbons and glufosinate were close to being statistically significant. Some suggestive dose-response relationships were observed for these same chemicals and inorganic 
compounds when the experts' scores were used. However, the results were not always consistent, and in some cases they differed substantially for the different indices. We do not have any straightforward explanation for this result. In the validation study for the questionnaire (35), the item "duration of treatments" had relatively low accuracy and reliability indices (sensitivity ranging between 0.40 and 0.50 , the weighted kappas ranging between 0.66 and 0.76 ). The duration of exposure in months was computed only for the acute risk period and could be a better approach to exposure during a relevant period than the duration of exposure in hours, expressing the mean number of hours per year involved in pesticide treatments during the 2 years covering the acute risk period.

The results of our research provide suggestive evidence with respect to the risk of congenital malformations for paternal exposure to some specific pesticides, notably pyridils, aliphatic hydrocarbons, inorganic compounds, and glufosinate. These findings warrant further investigation. This study did not find an increased risk for paternal exposure to pesticides in the classes of organophosphates, carbamates, organochlorines, chloroalkylthio fungicides, or organosulfurs.

\section{Acknowledgments}

This study was partially supported by grants from the Vicerectorado de Investigación de la Universidad de Valencia (code 1015, 1994) and from the Institut Valencià d'Estudis e Investigació (code 005/061, 1994).

We would like to thank Dr Valentín Esteban and Jose Luis Porcuna, the experts assessing the exposure to pesticides, for their highly valuable collaboration. Comments on the manuscript by Dr Miquel Porta are greatly appreciated.

\section{References}

1. Brent RL, Beckman DA. Environmental teratogens. Bull NY Acad Med 1990;66:123-63.

2. Olshan AF, Faustman EM. Male-mediated developmental toxicity. Ann Rev Public Health 1993;14:159-81.

3. Joffe JM. Influence of drug exposure of the father on perinatal outcome. Clin Perinatol 1979;6:21-35.

4. García AM. Occupational exposure to pesticides and congenital malformations: a review of mechanisms, methods and results. Am J Ind Med 1998;33:232-40.

5. Schardein JL. Chemically induced birth defects. New York (NY): Marcel Dekker Inc, 1985.

6. World Heath Organization (WHO). Public health impact of pesticides used in agriculture. Geneva: WHO, World Health Organization Office of Publications, 1990.

7. Hayes WJ, Laws ER, editors. Handbook of pesticide toxicolo- gy. San Diego (CA): Academic Press, 1991.

8. Fedrick $J$. Anencephalus in the Oxford record linkage study area. Dev Med Child Neurol 1976;18:643-56.

9. Dickson D. Herbicide claimed responsible for birth defects [letter]. Nature 1979;282:220.

10. Holmberg PC, Hernberg S. Congenital defects and occupational factors: a comparison of different methodological approaches. Scand J Work Environ Health 1979;5:328-32.

11. Hemminki K, Mutanen P, Luoma K, Saloniemi I. Congenital malformations by parental occupation in Finland. Int Arch Occup Environ Health 1980;46:93-8.

12. Smith AH, Matheson DP, Fisher DO, Chapman CJ, Preliminary report of reproductive outcomes among pesticide applicators using 2,4,5-T. NZ Med J 1981;93:177-9.

13. Smith AH, Fisher DO, Pearce N, Chapman CJ. Congenital defects and miscarriages among New Zealand 2,4,5-T sprayers. Arch Environ Health 1982;37:197-200.

14. Balarajan R, McDowall M. Congenital malformations and agricultural workers [letter]. Lancet 1983;1:1112-3.

15. Golding J, Sladden T. Congenital malformations and agricultural workers [letter]. Lancet 1983;1:1393.

16. Roan CC, Matanoski GE, McIlnay CQ, Olds KL, Pylant F, Trout JR, et al. Spontaneous abortions, stillbirths and birth defects in families of agricultural pilots. Arch Environ Health 1984;39:56-60.

17. Suskind RR, Hertzberg VS. Human health effects of 2,4,5-T and its toxic contaminants. JAMA 1984;251:2372-80.

18. Schwartz DA, Newsum LA, Markowitz Heifetz R. Parental occupation and birth outcome in an agricultural community. Scand J Work Environ Health 1986;12:51-4.

19. Schwartz DA, Logerfo JP. Congenital limb reduction defects in the agricultural setting. Am J Public Health 1988;78:6547 .

20. Tikkanen J, Kurppa K, Timonen H, Holmberg PC, Kuosma E, Rantala K. Cardiovascular malformations, work attendance and occupational exposures during pregnancy in Finland. Am J Ind Med 1988;14:197-204.

21. Restrepo M, Muñoz N, Day NE, Parra JE, de Romero L, Nguyen-Dinh X. Prevalence of adverse reproductive outcomes in a population occupationally exposed to pesticides in Colombia. Scand J Work Environ Health 1990;16:232-8.

22. Restrepo M, Muñoz N, Day N, Parra JE, Hernandez C, Blettner $\mathrm{M}$, et al. Birth defects among children born to a population occupationally exposed to pesticides in Colombia. Scand J Work Environ Health 1990;16:239_-46.

23. Rupa DS, Reddy PP, Redd OS. Reproductive performance in population exposed to pesticides in cotton fields in India. Environ Res 1991;55:123-8.

24. Olshan AF, Teschke K, Baird PA. Paternal occupation and congenital anomalies in offspring. Am J Ind Med 1991;20:447-75.

25. Lin S, Marshall EG, Davidson GK. Potential parental exposure to pesticides and limb reduction defects. Scand J Work Environ Health 1994;20:166-79.

26. Spagnolo A, Bianchi F, Calabro A, Calzolari E, Clementi M, Mastroiacovo P, et al. Anophthalmia and benomyl in Italy: a multicenter study based on 940,615 newborns. Reprod Toxicol 1994;8:397-403.

27. Garry V, Schreinemachers D, Harkins ME, Griffith J. Pesticide appliers, biocides, and birth defects in rural Minnesota. Environ Health Perspect 1996;104:394 -9.

28. Blatter BM, Roeleveld N. Spina bifida and parental occupation in a Swedish register-based study. Scand J Work Environ Health 1996;22:433-7. 
29. Siemiatycki J, Day NE, Fabry J, Cooper JA. Discovering carcinogens in the occupational environment: a novel epidemiologic approach. JNCI 1981;66:217-25.

30. Ciccone G, Vineis P. Inter-rater agreement in the assessment of occupational exposure to herbicides. Med Lav 1988;79:363-7.

31. Ponti A, Bosia S, Segnan N, Ronco G, Piccioni P, Luccoli L, et al. Comparison of methods of occupational exposure assessment in epidemiology: pesticides in vinegrowing (abstract). In: International Agency for Research on Cancer, Conference on retrospective assessment of occupational exposures in epidemiology: programme and abstracts. Lyon: International Agency for Research on Cancer, 1994:85.

32. de Cock J, Kromhout H, Heederik D, Burema J. Experts' subjective assessment of pesticide exposure in fruit growing. Scand J Work Environ Health 1996;22:425-32.

33. Segnan N, Ponti A, Ronco G, Kromhout H, Heederik D, de Cock J, et al. Comparison of methods for assessing the probability of exposure in metal plating, shoe and leather goods manufacture and vine growing. Occup Hyg 1996;3:199-208.

34. Butlletí d'Avisos [News Bulletin]. Servei de Sanitat Vegetal [Plant sanitation service]. Valencia (Spain): Consellería d'Agricultura i Pesca, Generalitat Valenciana, 1992. Suplements 2-4.

35. Orts E, García AM, Benavides FG, Fletcher T. Validación de un cuestionario para medir retrospectivamente la exposición laboral a plaguicidas [Validation of a questionnaire on retrospective assessment of occupational exposure to pesticides]. Gac Sanit 1997;11:274-80.

36. StataCorp. Stata Statistical Software: release 5.0. College Station (TX): Stata Corporation, 1997.

37. Selevan SG. Collaboration produces a whole that is greater than the sum of its parts [editorial]. Epidemiology 1997;8:340-1.

38. Khoury MJ, Botto L, Mastroiacovo P, Skjaerven R, Castilla E, Erickson JD. Monitoring for multiple congenital anomalies: an international perspective. Epidemiol Rev 1994;16:335-50.

39. Siemiatycki J, Dewar R, Richardson L. Costs and statistical power associated with five methods of collecting occupation exposure information for population-based case-control studies. Am J Epidemiol 1989;130:1236-46.

40. Clavel J, Glass DC, Cordier S, Hémon D. Standardization in the retrospective evaluation by experts of occupational exposure to organic solvents in a population-based case-control study. Int J Epidemiol 1993;22:S121-6.

41. Kauppinen TP, Pannett B, Marlow DA, Kogevinas M. Retrospective assessment of exposure through modeling in a study on cancer risks among workers exposed to phenoxy herbicides, chlorophenols and dioxins. Scand J Work Environ Health 1994;20:262-71.

42. Bond GG, Bodner KM, Sobel W, Schellenberger RJ, Flores GH. Validation of work histories obtained from interviews. Am J Epidemiol 1988;128:343-51.

43. Ahlborg GA Jr. Validity of exposure data obtained by questionnaire: two examples from occupational reproductive studies. Scand J Work Environ Health 1990;16:284-8.

44. Joffe M. Validity of exposure data derived from a structured questionnaire. Am J Epidemiol 1992;135:564-70.

45. Blair A, Zahm SH. Methodologic issues in exposure assessment for case-control studies of cancer and herbicides. Am J Ind Med 1990;18:285-93.

46. Brewster MA, Rupe W, Rafferty MH. Small area pesticides data: multiplicity and variability of pesticide usage on southern row crops. Arch Environ Contam Toxicol 1992;23:289 94.

47. Petrelli G, Siepi G, Miligi L, Vineis P. Solvents in pesticides [shorter communications]. Scand J Work Environ Health 1993; 19:63-5.

48. Hallenbeck WH, Cunningham-Burns KM. Pesticides and human health. New York (NY): Springer-Verlag, 1985.

49. El-Abidin-Salam AZ, Hussein EH, El-Itriby HA, Anwar WA, Mansour SA. The mutagenicity of Gramoxone (paraquat) on different eukariotic systems. Mutat Res 1993;319:89-101.

50. International Agency for Research on Cancer (IARC). Genetic and related effects. Lyon: IARC, 1987. Monographs on the evaluation of the carcinogenic risk of chemicals to humans, suppl 6.

51. Gilani SH, Alibhai Y. Teratogenicity of metals to chick embryos. J Toxicol Environ Health 1990;30:23 - 31.

52. Ebert E, Leist KH, Mayer D. Summary of safety evaluation toxicity studies of glufosinate ammonium. Food Chem Toxicol 1990;28:339—49.

Received for publication: 11 March 1998 